\title{
Kästner, literatura infantil e tradução
}

\author{
Simone Pereira Gonçalves
}

Erich Kästner nasceu em Dresden, no Leste alemão, em 23 de fevereiro de 1899. Era filho único, mas não sofria com isso, pois "Eu tinha amigos!" ${ }^{11}$ (KÄSTNER, 1957, apud LIST, 2010, p. 28). Desde criança queria ser professor e começou sua formação no magistério em 1913, mas logo teve de interrompê-la por ter sido convocado pelo Exército para a Primeira Guerra Mundial. Após a Guerra, estudou em Rostock e Leipzig, onde trabalhou como redator. No verão de 1927, mudou-se para Berlim para tentar a vida como escritor. Seus poemas satíricos faziam sucesso, assim como seus contos, críticas teatrais e reportagens.

Kästner era ambicioso e cheio de planos, mas literatura infantil não contava entre eles. Em Berlim trabalhou para a Weltbühne (palco do mundo), uma revista semanal de tendência de esquerda liberal e pacifista, cuja editora era Edith Jacobsohn, a viúva do fundador da revista, que costumava convidar os colaboradores em sua casa para o chá da tarde. Em uma dessas tardes, Edith, que era proprietária da renomada editora de livros infantis "William \& Co", recomendou a Kästner escrever livros infantis, pois segundo ela, havia uma escassez de bons autores alemães nesta área e nos contos de Kästner sempre havia personagens crianças. "O senhor entende do assunto. É só dar um passo. Escreva uma vez não só sobre crianças, senão para crianças!"2 (KÄSTNER, apud LIST, 2010, p. 91). O autor ficou perplexo com a sugestão e prometeu tentar. Seis sema-

1 [ich besaß ja Freunde] A tradução desta citação e de todas as seguintes, em que o original aparece em notas de rodapé, são de minha autoria.

2 [davon verstehen Sie eine ganze Menge. Es ist nur noch ein Schritt. Schreiben Sie einmal nicht nur über Kinder, sonder auch für Kinder] 
nas mais tarde, Edith ligou para Kästner para saber se ele havia refletido sobre sua proposta. Kästner respondeu: "Não só refleti como já estou no nono capítulo"3 (KÄSTNER, apud LIST, 2010, p. 91). E assim surgiu, no outono de 1928, sua obra infantil de maior sucesso, "Emil e os Detetives". Desde então, ele não parou mais de publicar livros para crianças. "Pünktchen und Anton" (Pontinho e Antônio), também ilustrado por Walter Trier, veio logo a seguir, em 1931.

Seus livros são marcados por uma linguagem enxuta e citadina, pela inversão de perspectiva e troca de papéis. Ao invés de lugares exóticos, comuns na literatura infantil, suas histórias não se passam em tempos remotos, mas na época contemporânea e seus heróis são crianças espertas da cidade grande que chamam os adultos à razão.

A tarefa do tradutor literário consiste em enfrentar um perigo duplo: o de destruir a alteridade do texto de partida na língua-alvo, transformando-o em uma tradução "que nem parece tradução" ou o de tornálo estrangeirado. Tomo essa asserção como um itinerário de tradução. É um esforço e também uma negociação contínua procurar transmitir aquela realidade apreendida pela minha imaginação - preservando sua alteridade - a um outro contexto cultural, histórico e linguístico que pressupostamente não tem o conhecimento do respectivo contexto de partida, sem contudo povoar a tradução de estrangeirices. $O$ ato tradutório abriga o desejo de alargar a capacidade significante e expressiva de uma língua.

Sugiro o título "Pontinho e Antônio" para "Pünktchen und Anton". Traduzi quase todos os nomes, primeiro por acreditar que, em se tratando de um livro para crianças, os nomes em português tornariam a leitura mais acessivel, mais direta para o pequeno leitor. Mas também pelo fato de os nomes conterem um significado, como o cachorro "Esnobe" e a governanta "srta. Devota". "Pünktchen" (Pontinho) não é nome próprio, é apelido, e todo apelido remete a alguma característica pessoal, que será mencionada no livro. Poderia deixar "Anton" para evidenciar a ambientação estrangei$\mathrm{ra}$, mas preferi a tradução do nome por estes serem nomes comuns em ambos os idiomas e também para não causar a impressão de que um personagem tem um nome português e o outro um nome alemão. $A$ governanta "Käte", cuja pronúncia em português não seria evidente, mesmo com a grafia "Kaete" ou aportuguesada para Kete, batizei de "Catita" por me parecer

3 [nicht nur das (...) ich schreibe gerade am neunten Kapitel] 
familiar e carinhoso, como variação de Cátia que também é um diminutivo de Catarina. Talvez a tradução do nome "Gotfried Klepperbein" para "Godofredo Pangaré" seja a mais ousada de todas. O significado dos sobrenomes germânicos é normalmente mais patente que o dos sobrenomes latinos, assim por exemplo, existem sobrenomes que vão desde "Moleiro" (Müller) e "Alfaiate" (Schneider) - os mais comuns - a "Malvado" (Böse), " Fornicador!" (Ficker) e até mesmo "Perna de Frango" (Hühnerbein). Como "Klepperbein" significa ao pé da letra "perna de pangaré", optei pelo sentido de pangaré que já implica pernas cansadas.

As expressões idiomáticas, que muitas vezes não têm equivalência na língua-alvo, exigem uma adaptação. Nesse caso, opta-se pela substituição por uma outra expressão de sentido aproximativo, e em geral com imagens diferentes, ou pela tradução ao pé da letra, se a expressão é compreensivel, ainda que incomum. Esta última alternativa é a que mais me agrada, simplesmente por se ter a sensação de sair da rotina linguageira e apresentar algo novo. Exemplo:

"Ela tinha o miolo mole porque tomava banho quente demais quando criança"

Embora eu não tenha conhecimento da mesma expressão em português, não vi necessidade de adaptar, procurar uma expressão substituta, por me parecer compreensível e até mesmo imaginá-la pronunciada como sabedoria popular de uma avó brasileira. Este me parece um bom exemplo de se manter a diferença sem incorrer em estrangeirices, ampliando a capacidade expressiva da língua, levando um pouco deste contexto cultural para um outro. $O$ banho quente na mentalidade alemã pode ter esta conotação negativa, hoje em dia, há uma outra expressão que seria mais ou menos em português "um ducha-quente" (Warmduscher), uma pessoa muito cômoda que preza bastante o conforto, que não possui a temeridade daqueles que tomam banho frio.

O texto também apresenta impasses, como o de transpor uma situação cotidiana específica da cultura local, procurando produzir o mesmo efeito cômico para o público-alvo. Aqui pode-se questionar: o que é fidelidade no ato tradutório? Traduzir tal como está no original ou procurar uma situação, embora diferente, que produza o mesmo efeito cômico?

4 [Sie war (...) sehr verrückt. Die hat man als Kind zu heiß gebadet] 
Esse questionamento vale para a passagem em que Pontinho na sua brincadeira de criança, disfarça-se de fiscal e pergunta a um "passageiro" (o pai dela) - provavelmente de um trem, bonde ou metrô - pelo seu tíquete. No sistema alemão não é comum a utilização de catracas nos transportes públicos. Em lugar disso, fiscais controlam ocasionalmente e à paisana. $E$ há sempre pessoas que viajam clandestinamente. O final do primeiro capítulo termina com uma expressão idiomática que desconheço em português, "Gottfried Klepperbein sah, wie es so schön heißt, in den Mond." Ao pé da letra, "ficou olhando a lua", o que significa sair sem nada, sair levando desvantagem, ficar a ver navios, ficar chupando o dedo. Optei nesse caso por "caiu das nuvens", que embora tenha outro sentido, o da decepção, desilusão, o de despertar de um bom sonho, é uma expressão pertinente à situação e a única que me ocorre com uma imagem que evoque o céu.

\section{Pontinho e Antônio}

\section{Primeiro Capítulo}

Pontinho brinca de teatro

Quando o senhor diretor Pogge chegou em casa ao meio-dia, ficou como que plantado e pasmo fixou o olhar na sala de estar. Lá estava Pontinho, sua filha, com o rosto voltado para a parede, fazendo continuamente reverências e se lamentando ao mesmo tempo. Será que ela está com dor de barriga?, pensou ele. Mas ele segurou a respiração e ficou parado. Pontinho estendia as duas mãos à parede revestida com um papel de parede prateado, reverenciava e dizia com a voz trêmula: "Fósforos, comprem fósforos, meus senhores!" Ao lado da menina se encontrava Esnobe, o pequeno dackel marrom de Pontinho, que mantinha a cabeça bem torta, admirado, e abanava o rabo ritmadamente. Pontinho, lamentosa, declarava:

- Tenha piedade de nós, os pobres. Uma caixa de fósforos custa apenas dez centavos.

Esnobe começou a coçar atrás da orelha. Talvez ele achasse o preço alto demais ou lamentasse por não ter dinheiro consigo. Pontinho estendia as mãos ainda mais alto, reverenciava e gague java: 
- A mamãe ficou completamente cega e ainda tão jovem. Três cai$x a s$ por vinte e cinco. Deus lhe pague, minha senhora!

Ao que parece, a parede comprara três caixas de fósforo dela.

O senhor Pogge deu uma risada bem alto. Algo assim não the tinha acontecido ainda. Lá estava sua filha na sala de estar, que havia custado três mil marcos, mendigando para a parede. Pontinho se assustou ao ouvir alguém rindo, virou-se, viu o pai e saiu correndo. Esnobe, indiferente, saiu pulando atrás dela.

- Vocês estão com um parafuso solto? - perguntou o pai, mas não obteve nenhuma resposta. Aí, ele virou-se e foi para o seu escritório. Sobre a sua escrivaninha havia cartas e jornais. Ele se enfiou na poltrona de couro, acendeu um charuto e se pôs a ler.

Pontinho se chamava, na verdade, Luísa, mas como nos seus primeiros anos de vida ela não queria crescer de jeito nenhum, passou a ser chamada de Pontinho. E continuava com este nome, apesar de já frequentar a escola há muito tempo e não ser mais tão pequena. $O$ pai dela, o sr. Pogge, era diretor de uma fábrica de bengalas. Ele ganhava muito dinheiro e tinha também muito trabalho. A mulher dele, a mãe de Pontinho, tinha outra opinião a esse respeito. Ela achava que ele ganhava muito pouco dinheiro e trabalhava demais. Então, ele sempre dizia: "Mulheres não entendem nada disso". Mas ela não acreditava nisso.

Eles moravam em um apartamento grande, que não ficava longe do Parlamento, na margem do rio Spree. O apartamento tinha dez cômodos e era tão grande que quando Pontinho voltava para o seu quarto, após as refeições, geralmente já estava com fome de novo, de tão longo que era o caminho!

Já que estamos falando de comida: $O$ sr. Pogge estava com fome $e$ tocou o sininho. Berta, a empregada que era gorda, entrou.

- A sra. quer que eu morra de fome? - perguntou irritado.

- De jeito nenhum! - disse Berta. - Mas a patroa ainda está na cidade e eu pensei...

O sr. Pogge se levantou.

- Se a senhora pensar mais uma vez, não terá permissão para sair amanhã - declarou ele. - Vamos! Comida! Chame a babá e a menina.

A gorda da Berta saiu nas carreiras e rolou pela porta.

$O$ sr. Pogge era o primeiro a estar na copa. Ele pegou um comprimido, fez uma careta e tomou água em seguida. Ele não perdia uma oportuni- 
dade de tomar remédios. Antes das refeições, após as refeições, antes de ir dormir, após levantar-se. Às vezes, eram comprimidos redondos, às vezes, eram bolinhas, às vezes, quadradinhos. Se poderia supor que ele gostasse de tomar remédio. Mas ele só tinha problemas de estômago.

Daí então, apareceu a srta. Devota. A srta. Devota era a governanta. Ela era bem alta, magricela e maluca.

- Ela tinha o miolo mole porque tomava banho quente demais quando criança, dizia sempre a gorda Berta, e as duas aguentavam bem uma à outra.

Antes, quando não havia nenhuma governanta na casa dos Pogge e a babá Catita ainda trabalhava lá, Pontinho sempre comia na cozinha junto com a Berta e a Catita. Ali elas lavavam vagens, Berta ia fazer compras com Pontinho e lhe contava do irmão que morava nos Estados Unidos. Naquela época, Pontinho sempre estava bem disposta e não vivia tão pálida como agora que a maluca da Devota morava em casa.

- Minha filha anda pálida. - disse o sr. Pogge preocupado. - A senhorita não acha?

- Não. - respondeu a srta. Devota.

Então, veio a Berta trazendo a sopa e rindo. A srta. Devota olhou de atravessado para a empregada.

- Por que a senhora está rindo feito boba? - perguntou o dono da casa e começou a comer como se fosse pago para isso. Mas de repente ele deixou cair a colher no meio da sopa, apertou o guardanapo na boca, engasgou, tossiu horrivelmente e apontou para a porta.

Lá estava Pontinho parada. Mas minha Nossa Senhora, com que aparência! Ela havia vestido o roupão vermelho do pai e enfiado um travesseiro por baixo, o que a deixava semelhante a uma chaleira redonda e amassada. As pernas finas e sem meias, espiando para fora, pareciam duas baquetas.

Na cabeça ficava dançando o chapéu de domingo de Berta que era um negócio genial de palha colorida. Em uma mão, Pontinho segurava o rolo de macarrão e um guarda-chuva aberto, na outra um barbante. No barbante estava amarrada uma frigideira e na frigideira, que ia batendo e balançando atrás da criança, estava sentado Esnobe, o dackel, com a testa franzida. Aliás, ele franzia a testa não por estar mal-humorado, mas por ter pele demais na cabeça. E como a pele não sabia para onde ir, formava ondas permanentes. 
Pontinho passeou em volta da mesa, parou em frente ao seu pai, olhou para ele avaliando-o e perguntou seriamente:

- Por gentileza, posso ver a sua passagem?

- Não. - disse o pai. - A senhora não está me reconhecendo? Mas eu sou o Ministro dos Transportes Ferroviários.

- Ah, é... - disse ela.

A srta. Devota levantou-se, pegou Pontinho pelo colarinho e a desfez até ela ficar com a aparência de uma criança normal. A gorda Berta recolheu a roupa, o rolo de macarrão, o guarda-chuva e levou tudo para fora da copa. Ela continuou rindo na cozinha. Podia-se ouvir muito bem.

- Como foi na escola? - perguntou o pai, mas como Pontinho não respondeu e ficou brincando com a sopa, ele perguntou novamente: - Quanto são três vezes oito?

- Três vezes oito? Três vezes oito são cento e vinte dividido por cinco. - disse ela.

O sr. Diretor Pogge não se abismava com mais nada. Ele calculou escondido e como estava certo, ele continuou a comer. Esnobe subira em uma cadeira vazia, apoiou as patinhas dianteiras na mesa e com a testa franzida ficou vigiando para que todos tomassem a sopa. Parecia que ele queria proferir um discurso. Berta trouxe frango com arroz e deu uma palmadinha no Esnobe. O dackel entendeu mal e subiu completamente na mesa. Pontinho o colocou novamente no chão e disse:

- O que eu mais gostaria era de ser gêmea.

$O$ pai encolheu os ombros como que lamentando.

- Seria magnífico. - disse a menina. - Nós nos vestiríamos iguais, teríamos a mesma cor de cabelo, o mesmo número de calçado, as mesmas roupas e a mesma, mesmíssima cara.

- E daí? - perguntou a srta. Devota.

Pontinho suspirava de prazer, enquanto imaginava a história com as gêmeas:

- Ninguém saberia quem sou eu e quem ela é. E se alguém pensasse que sou eu, seria ela. E se alguém pensasse que é ela, seria eu. Ah, isto seria deslumbrante.

- É duro de aguentar. - opinou o pai.

- E quando a professora chamasse por "Luísa!", então eu me levantaria e diria "Não, eu sou a outra." Aí, a professora diria "sentada!", chama- 
ria a outra e gritaria "Por que você não se levanta, Luísa?", e a outra diria "Mas eu sou a Carlinha." Três dias depois, a professora teria um ataque e receberia licença para repouso no sanatório, e nós entraríamos de férias.

- Gêmeos são normalmente muito diferentes. - afirmou a srta. Devota.

- Mas em todo caso, eu e a Carlinha, não. - retrucou Pontinho. Tanta semelhança assim vocês nunca viram. Nem mesmo o diretor saberia nos distinguir. $O$ diretor era o pai dela.

- Já estou farto de você. - disse o diretor e serviu-se de uma segunda porção de frango.

- O que você tem contra a Carlinha? - perguntou Pontinho.

- Luísa! - chamou ele levantando a voz.

Quando ele dizia "Luísa" significava obedecer ou bronca. Então, Pontinho calou-se, comeu frango com arroz e fez caretas escondido para o Esnobe, que estava agachado ao lado dela, até ele estremecer de medo e sair em disparada para a cozinha.

Quando eles estavam comendo a sobremesa - havia ameixas rainhacláudia -, apareceu finalmente a sra. Pogge. Ela era muito bonita, mas aqui entre nós, ela era bem insuportável. Berta, a empregada, disse uma vez a uma colega:

- Minha patroa devia ser liquidada com um golpe de trapo molhado. Tem uma criança tão simpática e engraçada, e um marido tão encantador, mas você acha que ela cuida dos dois? Mas nem sonhando. Ela passa o dia todinho batendo perna, fazendo compras, trocando mercadorias, indo aos chás das cinco, a desfiles de moda e à noite ainda por cima arrasta o pobre coitado: maratonas de bicicleta de seis dias, teatro, cinema, bailes, o diabo anda solto o tempo todo. Ela não para mais em casa, o que também tem o seu lado bom.

Então a sra. Pogge apareceu, sentou-se e estava chateada. Na verdade, ela deveria ter se desculpado por ter chegado tão tarde. Ao invés disso, se fez de ofendida por não terem esperado por ela para comer. $O$ sr. Pogge tomou novamente comprimidos, desta vez os quadradinhos, fez uma careta e, em seguida, tomou água.

- Não se esqueça que hoje à noite estamos convidados na casa do Cônsul Geral Ohlerich. - disse sua esposa.

- Não. - disse o sr. Pogge.

- O frango já está completamente frio. - disse ela. 
- Certamente. - disse a gorda Berta.

- Pontinho tem tarefa da escola para fazer? - perguntou ela.

- Não. - disse a srta. Devota.

- Filha, você está com um dente mole! - exclamou ela.

- Certamente. - disse Pontinho.

O sr. Pogge levantou-se da mesa:

- Já nem sei mais o que é estar em casa à noite.

- Mas ontem à noite nós nem sequer passamos da porta. - retrucou sua mulher.

- Mas os Brückmann estavam aqui. - disse ele. - Os Schramm e os Dietrich, a casa toda estava cheia.

- Estávamos em casa ontem ou não estávamos em casa ontem? perguntou ela energicamente e olhando para ele de modo impaciente. Por via das dúvidas, o sr. diretor Pogge não respondeu nada e foi para o escritório. Pontinho o seguiu e sentou-se com ele na grande poltrona de couro, pois lá havia lugar para dois.

- O dente está mole? - perguntou ele. - Está doendo?

- Que nada. - disse ela. - Qualquer hora eu arranco ele. Talvez ainda hoje.

Então, buzinaram em frente da casa. Pontinho acompanhou seu pai até a porta. Sr. Hollack, o chofer, a cumprimentou e ela o cumprimentou de volta. Ela fez exatamente como ele, colocando a mão no boné, embora ela não estivesse de boné. $O$ pai entrou, o carro partiu e o pai acenou. Pontinho acenou também.

Quando ela quis entrar em casa, Godofredo Pangaré estava parado diante da porta. Ele era o filho dos zeladores, um moleque malandro.

- Ei, você. - disse ele. - Se você me der dez marcos, eu não conto nada pra ninguém, senão eu conto pro seu pai.

- Contar o quê? - perguntou Pontinho sem maldade.

Godofredo Pangaré impediu a passagem de Pontinho com jeito de ameaça:

- Você sabe muito bem, não se faça de boba, coração!

Pontinho queria entrar em casa, mas ele não a deixou. Aí, ela parou ao lado dele, colocou as mãos para trás e olhou para o céu, espantada, como se estivesse passando um zepelim ou um besouro-de-maio de patins ou alguma coisa do gênero. 
E claro, o garoto também olhou para cima e aí ela correu passando por ele como um relâmpago, e Godofredo Pangaré, como se costuma dizer, caiu das nuvens.

\section{Pünktchen und Anton}

\section{Erstes Kapitel}

\section{Pünktchen spielt Theater}

Als Herr Direktor Pogge mittags heimkam, blieb er wie angewurzelt stehen und starrte entgeistert ins Wohnzimmer. Dort stand nämlich Pünktchen, seine Tochter, mit dem Gesicht zur Wand, knickste andauernd und wimmerte dabei. Hat sie Bauchschmerzen? , dachte er. Aber er hielt die Luft an und rührte sich nicht von der Stelle. Pünktchen streckte der silbern tapezierten Wand beide Arme entgegen, knickste und sagte mit zitternder Stimme: „Streichhölzer, kaufen Sie Streichhölzer, meine Herrschaften!" Neben dem Kind kauerte Piefke, Pünktchens kleiner brauner Dackel, hielt den Kopf ganz schief, wunderte sich und klopfte mit dem Schwanz den Takt dazu. Pünktchen erklärte kläglich: „Haben Sie doch ein Herz mit uns armen Leuten. Die Schachtel nur zehn Pfennige." Piefke, der Hund, begann sich hinterm Ohr zu kratzen. Wahrscheinlich fand er den Preis zu hoch, oder er bedauerte, dass er kein Geld bei sich hatte.

Pünktchen streckte die Arme noch höher, knickste und stammelte: "Mutter ist völlig erblindet und noch so jung. Drei Schachteln fünfundzwanzig. Gott segne Sie, liebe Dame!" Anscheinend hatte ihr die Wand drei Schachteln Streichhölzer abgekauft.

Herr Pogge lachte laut. So etwas war ihm noch nicht vorgekommen. Da stand seine Tochter in dem Wohnzimmer, das dreitausend Mark gekostet hatte, und bettelte die Tapete an. Pünktchen erschrak, als sie jemanden lachen hörte, drehte sich um, sah den Vater und riss aus. Piefke hoppelte teilnahmslos hinterher.

"Bei euch piept's wohl?", fragte der Vater, aber er bekam keine Antwort. Da machte er kehrt und ging in sein Arbeitszimmer. Auf dem 
Schreibtisch lagen Briefe und Zeitungen. Er setzte sich tief in den Ledersessel, zündete sich eine Zigarre an und las.

Pünktchen hieß eigentlich Luise. Aber weil sie in den ersten Jahren gar nicht hatte wachsen wollen, war sie Pünktchen genannt worden. Und so hieß sie auch jetzt noch, obwohl sie längst zur Schule ging und gar nicht mehr klein war. Ihr Vater, der Herr Pogge, war Direktor einer Spazierstockfabrik. Er verdiente viel Geld, und viel zu tun hatte er auch. Seine Frau, Pünktchens Mutter, war allerdings anderer Meinung. Sie fand, er verdiene viel zu wenig Geld und arbeite viel zu viel. Er sagte dann immer: "Davon verstehen Frauen nichts." Aber das konnte sie nicht recht glauben.

Sie wohnten in einer großen Wohnung, nicht weit vom Reichstagsufer. Die Wohnung bestand aus zehn Zimmern und war so groß, dass Pünktchen, wenn sie nach dem Essen ins Kinderzimmer zurückkam, meist schon wieder Hunger hatte. So lang war der Weg!

Weil wir gerade vom Essen sprechen: Herr Pogge hatte Hunger. Er klingelte. Berta, das dicke Dienstmädchen, trat ein. "Soll ich verhungern?", fragte er ärgerlich.

"Bloß nicht!”, sagte Berta. "Aber die gnädige Frau ist noch in der Stadt, und ich dachte..."

Herr Pogge stand auf. "Wenn Sie noch einmal denken, kriegen Sie morgen keinen Ausgang", erklärte er. "Los! Essen! Rufen Sie das Fräulein und das Kind." Die dicke Berta setzte sich in Trab und kugelte durch die Tür.

Herr Pogge war der Erste im Speisezimmer. Er nahm eine Tablette, verzog das Gesicht und trank Wasser hinterher. Er schluckte Tabletten, so oft sich dazu Gelegenheit bot. Vor dem Essen, nach dem Essen, vorm Schlafengehen, nach dem Aufstehen, manchmal waren es kreisrunde Tabletten, manchmal kugelrunde, manchmal viereckige. Man hätte vermuten können, es mache ihm Spaß. Er hatte es aber nur mit dem Magen.

Dann erschien Fräulein Andacht. Fräulein Andacht war das Kinderfräulein. Sie war sehr groß, sehr mager und sehr verrückt.

"Die hat man als Kind zu heiß gebadet", erzählte die dicke Berta immer, und die beiden konnten einander auch sonst gut leiden. Früher, als es bei Pogges noch kein Kinderfräulein gab und als noch das Kindermädchen Käte da war, hatte Pünktchen immer bei Berta und Käte in der Küche gesessen. Da hatten sie Schoten ausgepult, und Berta war mit Pünktchen einkaufen gegangen und hatte ihr von ihrem Bruder in Amerika erzählt. 
Und Pünktchen war immer wohl und munter gewesen und hatte nicht so blass ausgesehen wie jetzt, wo die verrückte Andacht im Hause war.

"Meine Tochter sieht blass aus", sagte Herr Pogge besorgt. "Finden Sie nicht auch?"

"Nein", erwiderte Fräulein Andacht. Dann brachte Berta die Suppe und lachte. Fräulein Andacht schielte zu dem Dienstmädchen hinüber. "Was lachen Sie denn so dämlich?", fragte der Hausherr und löffelte, als kriege er es bezahlt. Aber plötzlich ließ er den Löffel mitten in die Suppe fallen, presste die Serviette vor den Mund, verschluckte sich, hustete entsetzlich und zeigte zur Tür.

Dort stand Pünktchen. Aber, du grüne Neune, wie sah sie aus! Sie hatte die rote Morgenjacke ihres Vaters angezogen und ein Kopfkissen darunter gewürgt, sodass sie einer runden verbeulten Teekanne glich. Die dünnen nackten Beine, die unter der Jacke vorguckten, wirkten wie Trommelstöcke.

Auf dem Kopf schaukelte Bertas Sonntagshut. Das war ein tolles Ding aus buntem Stroh. In der einen Hand hielt Pünktchen das Nudelholz und einen aufgespannten Regenschirm, in der anderen einen Bindfaden. An den Bindfaden war eine Bratpfanne festgebunden, und in der Bratpfanne, die klappernd hinter dem Kind hergondelte, saß Piefke, der Dackel, und runzelte die Stirn. Übrigens runzelte er die Stirn nicht etwa, weil er verstimmt war, sondern er hatte zu viel Haut am Kopf. Und weil die Haut nicht wusste, wohin, schlug sie Dauerwellen.

Pünktchen spazierte einmal rund um den Tisch, blieb dann vor ihrem Vater stehen, betrachtete ihn prüfend und fragte ernsthaft: "Kann ich mal die Fahrscheine sehen?"

"Nein", sagte der Vater. "Erkennen Sie mich denn nicht? Ich bin doch der Eisenbahnminister."

"Ach so", sagte sie.

Fräulein Andacht stand auf, packte Pünktchen beim Kragen und rüstete sie $a b$, bis sie wieder wie ein normales Kind aussah. Die dicke Berta nahm das Kostüm und das Nudelholz und den Regenschirm und brachte die Sachen hinaus. Sie lachte noch in der Küche. Man konnte es ganz deutlich hören.

"Wie war's in der Schule?", fragte der Vater, und weil Pünktchen nicht antwortete, sondern in der Suppe herumplanschte, fragte er gleich weiter: "Wie viel ist drei mal acht?" 
"Drei mal acht? Drei mal acht ist einhundertzwanzig durch fünf", sagte sie. Herr Direktor Pogge wunderte sich über gar nichts mehr. Er rechnete heimlich nach, und weil's stimmte, aß er weiter. Piefke war auf einen leeren Stuhl geklettert, stützte die Vorderpfoten auf den Tisch und gab stirnrunzelnd Obacht, dass alle ihre Suppe aßen. Es sah aus, als wolle er eine Rede halten. Berta brachte Huhn mit Reis und gab Piefke einen Klaps. Der Dackel verstand das falsch und kroch völlig auf den Tisch. Pünktchen setzte ihn auf die Erde hinunter und sagte: „Am liebsten möchte ich ein Zwilling sein."

Der Vater hob bedauernd die Schultern.

"Das wäre großartig, sagte das Kind. Wir gingen dann beide gleich angezogen und hätten die gleiche Haarfarbe und die gleiche Schuhnummer und gleiche Kleider und ganz, ganz gleiche Gesichter."

"Na und?", fragte Fräulein Andacht.

Pünktchen stöhnte vor Vergnügen, während sie sich die Sache mit den Zwillingen ausmalte. "Keiner wüsste, wer ich bin und wer sie ist. Und wenn man dächte, ich bin es, ist sie es. Und wenn man dächte, sie ist es, dann bin ich's. Hach, das wäre blendend..."

"Nicht zum Aushalten" meinte der Vater.

"Und wenn die Lehrerin "Luise!" riefe, dann würde ich aufstehen und sagen: "Nein, ich bin die andere." Und dann würde die Lehrerin "Setzen!" sagen und die andere aufrufen und schreien: "Warum stehst du nicht auf, Luise?", und die würde sagen: "Ich bin doch Karlinchen." "Und nach drei Tagen bekäme die Lehrerin Krämpfe und Erholungsurlaub fürs Sanatorium, und wir hätten Ferien."

"Zwillinge sehen meist sehr verschieden aus", behauptete Fräulein Andacht.

"Karlinchen und ich jedenfalls nicht", widersprach Pünktchen. "So was von Ähnlichkeit habt ihr noch nicht gesehen. Nicht mal der Direktor könnte uns unterscheiden." Der Direktor, das war ihr Vater.

"Ich habe schon an dir genug" sagte der Direktor und nahm sich die zweite Portion Huhn.

"Was hast du gegen Karlinchen?", fragte Pünktchen.

"Luise!", rief er laut. Wenn er "Luise" sagte, dann hieß das, jetzt wird pariert oder es setzt was. Pünktchen schwieg also, aß Huhn mit Reis und schnitt Piefke, der neben ihr kauerte, heimlich Grimassen bis der sich vor Entsetzen schüttelte und in die Küche sauste. 
Als sie beim Nachtisch saßen, es gab Reineclauden, erschien endlich Frau Pogge. Sie war zwar sehr hübsch, aber, ganz unter uns, sie war auch ziemlich unausstehlich.

Berta, das Dienstmädchen, hatte mal zu einer Kollegin gesagt: „Meine Gnädige, die sollte man mit 'nem nassen Lappen erschlagen. Hat so ein nettes, ulkiges Kind und so einen reizenden Mann, aber denkst du vielleicht, sie kümmert sich um die zwei? Nicht in die Tüte. Den lieben langen Tag kutschiert sie in der Stadt rum, kauft ein, tauscht um, geht zu Fünf-UhrTees und zu Modevorführungen, und abends muss dann der arme Mann auch noch mitstolpern. Sechstagerennen, Theater, Kino, Bälle, dauernd ist der Teufel los. Nach Hause kommt sie überhaupt nicht mehr. Na, das hat ja nun wieder sein Gutes."

Frau Pogge erschien also, setzte sich nieder und war gekränkt. Eigentlich hätte sie sich entschuldigen sollen, dass sie so spät kam. Stattdessent tat sie beleidigt, weil man mit dem Essen nicht gewartet hatte. Herr Pogge nahm wieder Tabletten, diesmal viereckige, verzog das Gesicht und trank Wasser hinterher.

"Vergiss nicht, dass wir heute Abend bei Generalkonsul Ohlerich eingeladen sind" sagte seine Frau.

"Nein", sagte Herr Pogge.

"Das Huhn ist ganz kalt", sagte sie.

"Jawohl" sagte die dicke Berta.

"Hat Pünktchen Schularbeiten auf?", fragte sie.

"Nein" sagte Fräulein Andacht.

"Kind, bei dir ist ja ein Zahn locker!", rief sie.

"Jawohl" sagte Pünktchen. Herr Pogge stand vom Tisch auf. „Wie es abends bei uns zu Hause ist, weiß ich schon gar nicht mehr."

"Dabei sind wir gestern Abend nicht bis vor die Tür gekommen" entgegnete seine Frau. "Aber Brückmanns waren da", sagte er, "und Schramms und Dietrichs, die ganze Bude war voll".

"Waren wir gestern zu Hause oder waren wir gesternnicht zu Hause?", fragte sie energisch und sah ihn gespannt an. Herr Direktor Pogge antwortete vorsichtshalber nichts und ging ins Arbeitszimmer. Pünktchen folgte ihm und setzte sich zu ihm in den großen Ledersessel, denn da war Platz für beide.

"Der Zahn ist locker?", fragte er." Tut es weh?" 
"Ach wo", sagte sie. "Den reiß ich mir gelegentlich raus. Vielleicht heute noch."

Dann hupte es vor dem Haus. Pünktchen brachte ihren Vater bis vor die Haustür. Herr Hollack, der Schofför, grüßte sie, und sie grüßte inn wieder. Sie machte das genau wie er, sie legte die Hand an die Mütze, obwohl sie gar keine Mütze aufhatte. Der Vater stieg ein, das Auto fuhr $a b$, der Vater winkte. Pünktchen winkte wieder.

Als sie ins Haus zurückgehen wollte, stand Gottfried Klepperbein vor der Tür, das war der Sohn von den Portierleuten, ein ausgemachter Lümmel.

"Du, sagte er, „wenn du mir zehn Mark gibst, verrat ich's nicht. Sonst sag ich's deinem Vater."

"Was denn?", fragte Pünktchen harmlos.

Gottfried Klepperbein vertrat ihr drohend den weg. "Das weißt du schon ganz gut, stell dich nicht so dumm, mein Herzblatt!"

Pünktchen wollte gern ins Haus, aber er ließ sie nicht hinein. Da stellte sie sich neben ihn, legte die Hände auf den Rücken und blickte erstaunt nach dem Himmel, als ob der Zeppelin käme oder ein Maikäfer auf Schlittschuhen oder so etwas.

Der Junge guckte natürlich auch hinauf, und da rannte sie wie der Blitz an ihm vorbei, und Gottfried Klepperbein sah, wie es so schön heißt, in den Mond.

\section{Referências}

KÄSTNER, Erich. Pünktchen und Anton. Hamburg: Cecile Dressler Verlag GmbH, 2009.

LIST, Sylvia. Das Große Erich Kästner Lesebuch. München: Deutscher Taschenbuch Verlag, 2010. 